rev.relac.int.estrateg.segur.10(1):181-202,2015

\title{
PERSPECTIVAS COMPARADAS DE LA PRESENCIA DE LA POLICÍA DURANTE EL CONFLICTO Y EL POSTCONFLICTO: LOS CASOS DE GUATEMALA, EL SALVADOR, IRLANDA DEL NORTE, AFGANISTÁN Y REPUBLICA DEL SUR DE SUDÁN
}

\author{
Jefferson Jaramillo Marín**
}

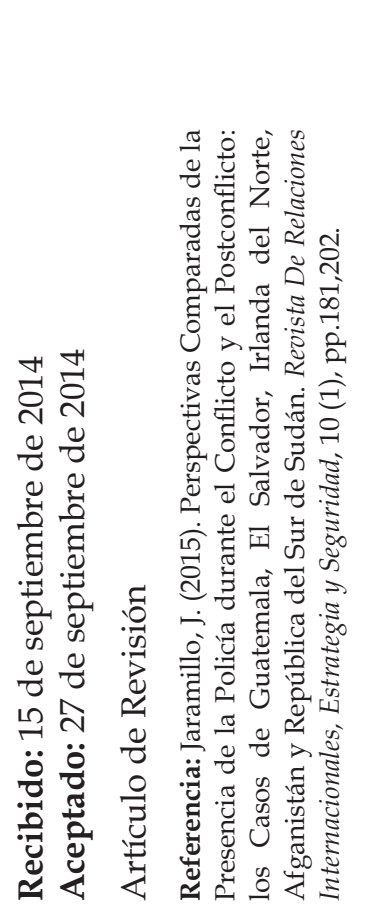

\section{RESUMEN}

En éste artículo se analizan cinco casos emblemáticos de países que experimentaron transiciones totales o parciales desde la confrontación armada irregular hacia un estado de relativa seguridad. Los casos analizados fueron Afganistán, Guatemala, Irlanda del Norte, Salvador y el sur de Sudán. El abordaje de los casos se hizo a partir de revisión de fuentes documentales secundarias y bajo una perspectiva comparada. Las fuentes revisadas permiten subrayar,

* Este artículo de revisión es resultado del proyecto de investigación titulado El rol de la Policía Nacional de Colombia en el Posconflicto. Este proyecto se desarrolló entre febrero y diciembre del 2013 y fue financiado por la Dirección Nacional de Escuelas - Escuela de Postgrados de la Policía Nacional. Se inscribe en el grupo de investigación INVESPOL-DINAE Análisis y reflexiones desde la academia en campos y áreas afines al quehacer policial, coordinado por la socióloga Alba Luz Molina Garzón y reconocido en categoría D en el año 2014, por el Programa Nacional de Ciencia y Tecnología (Colciencias). Agradecimientos, entre otras personas, especialmente a Erika Paola Parrado, estudiante de las carreras de Historia y Ciencia Política de la Pontificia Universidad Javeriana por la revisión y notas en torno a varias fuentes secundarias que sirvieron de base para la elaboración del artículo.

** Director Dpto. Sociología de la Pontificia Universidad Javeriana. Doctor en Investigación en Ciencias Sociales, FLACSO - México. jefferson.jaramillo@ javeriana.edu.co. 
en los casos analizados, la necesidad de romper con las estructuras simbólicas y materiales que contribuyeron o fueron parte de la violencia contra los civiles. En cada uno de los casos analizados, la Policía tuvo actuaciones cuestionables durante la confrontación armada, pero también fue objeto de variadas reformas en el período de transición a la normalización de la situación de seguridad. Éste documento ofrece claves de discusión para validar, en posteriores ejercicios de indagación cualitativos y cuantitativos, el papel que la policía ha tenido en el conflicto colombiano y lo que se espera de ella en una etapa posterior al conflicto.

Palabras clave: Conflicto Armado, Conflicto colombiano, Fuerza Pública, Policías Nacionales, Postconflicto.

\title{
COMPARATIVE PERSPECTIVES ON THE ROLE OF THE POLICE DURING THE CONFLICT AND POST-CONFLICT: THE CASES OF GUATEMALA, EL SALVADOR, NORTHERN IRELAND, AFGHANISTAN AND REPUBLIC OF SOUTH SUDAN
}

\begin{abstract}
In this article, discusses five emblematic cases of countries that have experienced full or partial transitions from irregular armed confrontation to a state of relative safety. The cases analyzed were Afghanistan, Guatemala, Northern Ireland, Salvador and southern Sudan. This approach was made on the basis of review of documentary sources and secondary under a comparative perspective. The revised sources allow understand, in the cases analyzed, the need to break with the symbolic and materials structures that contributed to or were part of the violence against civilians. In each of the cases analyzed, the police had questionable actions during the armed confrontation, but it was also subject to various reforms in the transition period to the normalization of the security situation. This discussion paper document provides keys to validate, in quantitative and qualitative research subsequent (discussion in subsequent exercise of qualitative and quantitative inquiry), the role that the police have had in the Colombian conflict and what is expected of them in a post-conflict phase.
\end{abstract}

Keywords: Armed Conflict, Armed Forces, colombian Conflict, national Police, Public Forces, Post-Conflict.

\section{PERSPECTIVAS COMPARADAS DO ROLE DA POLÍCIA DURANTE O CONFLITO E O PÓS- CONFLITO: OS CASOS DO GUATEMALA, O SALVADOR, O IRLANDA DO NORTE, O AFEGANISTÃO E A REPÚBLICA DO SUDÃO DO SUL}

\section{RESUMO}

Neste artigo, cinco casos representativos de países que experimentaram transições totais ou parciais de confronto armado irregular a um estado de análises de segurança relativa. Os casos 
analisados foram o Afeganistão, Guatemala, Irlanda do Norte, Salvador e o Sudão do Sul. Dirigindo casos feitos a partir de revisão de fontes documentais secundárias e uma abordagem comparativa. As fontes de estresse revistas permitir, nos casos analisados, a necessidade de romper com as estruturas simbólicas e materiais que contribuíram para ou faziam parte da violência contra civis. Em cada um dos casos analisados, a polícia teve ações questionáveis durante o confronto armado, mas também foi alvo de várias reformas no período de transição para a normalização da situação de segurança. Este documento de discussão fornece chaves para validar, nos anos subsequentes de pesquisa qualitativa e quantitativa, o papel da polícia tiveram no conflito colombiano eo que se espera deles em fase de pós-conflito.

Palavras-chave: Conflito Armado, Conflito colombiano, Força Pública, Policías Nacionais, PósConflito.

\section{INTRODUCCIÓN}

La Policía Nacional en Colombia enfrenta desde hace ya varios años, entre otros retos principales, la lucha contra los grupos armados ilegales, el combate a todas las modalidades de delitos y la garantía de la seguridad y convivencia de los ciudadanos. Con el fin de tener elementos de discusión sobre el rol que la Policía ha asumido en un país en medio del conflicto y lo que se esperaría de ella en una etapa de posconflicto ${ }^{1}$, este artículo de revisión considera central examinar, en clave comparada, algunas experiencias de Policías Nacionales, específicamente en algunos países que vivieron completa o parcialmente, situaciones de transición de la confrontación armada a un estado de seguridad relativa, posconflicto. Los procesos y experiencias que tomaremos como casos, a partir de una revisión documental secundaria, son los de Afganistán, Guatemala, Irlanda del Norte, Salvador y Sudán del Sur. Los mismos pueden ser considerados dentro de la categoría de conflictos armados prolongados, con episodios de guerra civil, como podría ser el caso también de Colombia.

Se entiende aquí guerra civil, como aquel "enfrentamiento sangriento entre ciudadanos derivado de la intensificación de la enemistad al interior de una unidad política, en el contexto de una soberanía escindida" (Uribe, 2013, p.85). Los países referenciados presentan de forma adicional debilidad en los procesos de construcción estatal, altos niveles de pobreza e inestabilidad en términos del régimen político y las libertades civiles.

Los procesos vividos por estos Estados nos llevan a considerar que dos de ellos (Guatemala e Irlanda del Norte), son del tipo de conflictos internos, según la definición propuesta por Uppsala

1. A falta de una mejor expresión utilizamos este término a lo largo del artículo, aunque somos conscientes que amerita un mayor cuidado conceptual, especialmente por la especificidad del contexto colombiano y por el facilismo con el que se viene utilizando la noción en espacios de decisión política. 
Conflict Data Program (UCDP) y el Centro de Estudios para las Guerras Civiles del Instituto Internacional de Investigaciones sobre la Paz de Oslo. Es decir, que estos países estuvieron inmersos en contiendas en las que tuvo lugar el uso de la fuerza entre dos partes, una de las cuales fue el gobierno de un Estado y la otra uno o más grupos de oposición, sin que operara necesariamente la intervención de otros Estados. Los otros tres, es decir Afganistán, Salvador y Sudán de Sur serían del tipo de conflictos internos internacionalizados, o con presencia de acciones violentas entre el gobierno de un Estado y uno o más grupos de oposición, con la intervención directa de otros Estados o partes secundarias a los mismos. En estos dos últimos casos, pese a que no necesariamente se reconozcan las intervenciones, éstas se llevan a cabo de forma directa o indirecta, como fue el caso de los EEUU en cada uno de ellos.

Bajo la noción de conflictos internos con episodios de guerra civil, se asume en el artículo que las partes enfrentadas están sujetas a una autoridad central, incurriendo entonces en las dinámicas de violencia dentro de las fronteras de una entidad soberana. Así, el proceso de transición de un conflicto doméstico a una guerra civil -según Kalyvas (2004)-, se lleva a cabo mediante la configuración de este en una confrontación militar directa, que puede o no incluir (como en los casos a comparar) criterios de soberanía fragmentada manejados de forma simultánea. Aquí las partes opositoras a la autoridad pueden ser o no reconocidas por el Estado.

En la descripción de los casos contemplados y a partir de la literatura revisada se considera la siguiente hipótesis de trabajo: durante el desarrollo de los conflictos armados prolongados, algunos agentes del Estado incurrieron en violaciones al DIH (Derecho internacional humanitario) y a los DDHH (Derechos humanos), bien sea por acción, omisión, connivencia o aquiescencia, lo que hizo necesario reformar la institucionalidad policial, específicamente, el replanteamiento de sus funciones en los escenarios de posconflicto.

Para el caso colombiano, reconocemos que el análisis generado desde la literatura revisada, solo ha pretendido extraer algunas lecciones históricas de otros contextos internacionales, de cara a un eventual escenario de posacuerdos y posconflicto en Colombia, que conlleve a replantear algunas de las funciones de esta institucionalidad. En este sentido, consideramos que el análisis propuesto debe complementarse con el desarrollo de estudios de corte cualitativo y cuantitativo que permitan evidenciar el impacto o no, de las transformaciones operadas en la institucionalidad policial colombiana en la generación de escenarios de paz, tanto locales como regionales.

\section{CONFLICTOS INTERNOS PROLONGADOS EN PERSPECTIVA COMPARADA Y LA NECESIDAD DE REFORMAS POLICIALES}

La intención de este apartado del artículo se enfoca en comprender, a partir de una breve descripción de las dinámicas nacionales de conflictos internos prolongados, qué tipo de reformas resultaron al aparato policial y a qué necesidades específicas de éstas sociedades respondieron respecto de la particularidad de sus escenarios de posconflicto. 


\section{GUATEMALA}

El conflicto guatemalteco experimentado entre 1966-1996, fue la expresión de una violencia derivada de varios factores estructurales como la herencia colonial de sus instituciones políticas excluyentes, la existencia de parámetros racistas en las relaciones interétnicas de un país profundamente pluricultural, la inequitativa distribución de la tierra, los altos índices de pobreza y la sucesión de dictaduras militares que profundizaron la amplia brecha entre distintos sectores de la sociedad (Sanford, 2003).

La estructura de este conflicto interno irregular se cimentó en diferentes valores y cosmovisiones de los actores envueltos directa o indirectamente en la confrontación. De una parte, una población indígena maya que conformaba el $60 \%$ del total de la población y que por siglos tejió con el territorio una relación densa de identificación cultural (Jaramillo, 2009). De otra parte, una serie de gobiernos militares que personificaron los intereses de una élite socioeconómica que, enmarcada en el contexto internacional, buscó perpetuar un sistema autoritario para controlar la economía nacional. También estuvieron los grupos guerrilleros, cuyas reivindicaciones fueron de naturaleza política armada y apuntaron a la superación de la segregación, en algunos momentos de su lucha. Finalmente, las multinacionales que hacían presencia en el país y que desempeñaron un papel fundamental en el desarrollo de las hostilidades, con el fin de facilitar la extracción de recursos primarios del territorio (Sanford, 2003).

Estas posiciones e intereses derivaron en una confrontación entre el Gobierno guatemalteco junto con las PAC (Patrullas de Autodefensa Civil2), y los grupos guerrilleros (EGP - Ejército Guerrillero de los pobres; FAR - Fuerzas Armadas Rebeldes; ORPA - Organización del Pueblo en Armas y PGT - Partido Guatemalteco del Trabajo), todas ellas agrupadas posteriormente en la URNG - Unidad Revolucionaria Nacional Guatemalteca. Esta confrontación estuvo orientada por la concepción del indígena como enemigo interno, justificando así violaciones masivas y sistemáticas a los DDHH y la concreción de actos de genocidio en contra de la comunidad Maya (Jaramillo, 2009).

La militarización de la vida cotidiana de las poblaciones fue un aspecto que definió las dinámicas del conflicto y consistió en la implementación de estructuras de autodefensa entrenadas y apoyadas por el Estado, como parte de su estrategia contrainsurgente. Según la Comisión de Esclarecimiento Histórico (CEH), durante los años setenta y ochenta, un 96\% de los asesinatos correspondieron a ejecuciones realizadas por el Ejército, la Policía Nacional y la Guardia de Hacienda. El 83\% de los hechos de victimización fueron contra comunidades mayas de los altiplanos. La violencia continuó hasta 1994, cuando comenzó el proceso de paz que duró hasta 1996 y culminó con la firma de múltiples acuerdos de negociación, la creación de la CEH y la desmovilización y reintegración de la UNRG (Rostica, 2006).

2. Las Patrullas de Autodefensa Civil fueron grupos armados creados y legalizados mediante el Acuerdo Gubernativo 222 de 1983, con la finalidad de militarizar a la población civil guatemalteca (Ramírez, 2007). 
Tras la firma de los acuerdos de paz en 1996, se plantearon una serie de reformas en relación con la institucionalidad policial ${ }^{3}$, que básicamente podemos resumir en:

a. La conformación de una Policía multiétnica y pluricultural, que partiera del reconocimiento y respeto del carácter diverso de la población guatemalteca y que tuviera esta dimensión en cuenta al momento del reclutamiento, selección, capacitación y despliegue del personal policial (Contreras y Sinay, 2004).

b. La desmilitarización de la Policía, que conllevara a la transformación y al tránsito simbólico de una estructura policiva militarizada a una de cuerpo de naturaleza civil, por medio del cambio de los nombres de los grados utilizados por el Ejército Nacional a los propios de una institución policial (Contreras y Sinay, 2004).

c. La separación de las actividades policiales de las militares, que posibilitara situar a la Policía Nacional bajo el Ministerio de Gobernación y no bajo el Ministerio de Defensa. Así, las funciones de prevención del delito e investigación criminal pasarían exclusivamente a la Policía Nacional Civil (Oliva, 2012).

d. Dimensionar con principio de realidad un nuevo escenario de delincuencia, dado que en un contexto de posconflicto, disminuiría el conflicto armado pero se incrementarían otros conflictos, por ejemplo, el delito común una vez fuera pactada la paz. Esto conllevó comprender que esta nueva institucionalidad policial debía estar preparada (aunque esto no se logró en términos reales) para asumir la generalización de nuevas formas de inseguridad derivadas del olvido de las causas estructurales del conflicto y las carentes oportunidades económicas existentes en el permanente estado de pobreza del país. De hecho, hasta el día de hoy, los crímenes relacionados con el surgimiento de pandillas (conocidas como Maras y expandidas por otros países de América Central), se convirtieron en la situación reinante del posconflicto en Guatemala (Cruz, 2006).

e. La necesidad de coordinación interinstitucional, aunque precisamente lo que imperó fue la poca coordinación y la ineficiencia entre las capturas por parte de la Policía y la respuesta del sistema judicial para penalizar a los delincuentes. Esta situación se agravó dadas las pésimas condiciones de reclusión en los centros penitenciarios y la corrupción de algunos funcionarios públicos (Sieder, 2003).

\section{EL SALVADOR}

El conflicto salvadoreño tuvo lugar desde 1980 hasta la firma de un acuerdo de paz en 1992 y cobró la vida de 75.000 personas (Allison, 2012). Básicamente fue una confrontación

3. La nueva policía se crea tras el Decreto legislativo 11 de 1997.

PERSPECTIVAS COMPARADAS DE LA PRESENCIA DE LA POLICÍA DURANTE EL CONFLICTO Y EL POSTCONFLICTO: LOS CASOS DE GUATEMALA, EL SALVADOR, IRLANDA DEL NORTE, AFGANISTÁN Y REPUBLICA DEL SUR DE SUDÁN 
armada entre el Estado (apoyado por EEUU) y el Frente de Liberación Nacional Farabundo Martí (FMLN), movimiento político-armado apoyado por los gobiernos de Nicaragua, Cuba y de la URSS. A la raíz del conflicto estaba la disputa por el acceso a la tierra, distribuida inequitativamente desde tiempos coloniales y mantenida por una élite resguardada por los gobiernos militares que se sucedieron en la historia de este país después de su independencia (Gonzales y Romano, 2000).

Una de las características de este conflicto fue que EEUU se involucró buscando frenar el significativo avance militar del FMLN, lo que conllevó a que las Fuerzas Armadas del Salvador lograran mejorar su capacidad de combate en la lucha contrainsurgente. La intensificación de la confrontación armada entre el gobierno y el FMLN tuvo serias repercusiones en la población civil campesina que fue objeto de violación de los derechos fundamentales, a través de masacres y desplazamiento forzado.

La confrontación abarcó gran parte del territorio, permeando organizaciones sociales, sindicales y comunales que buscaron también aunar esfuerzos por encontrar una salida política negociada al conflicto armado. Si bien el FMLN hizo uso de la violencia directa, la mayoría de violaciones a los DDHH fueron cometidas por agentes del Estado salvadoreño y sus fuerzas de seguridad. De hecho, la Comisión de la Verdad para el Salvador señaló que a principios de los ochenta, la Fuerza Armada Salvadoreña cometió una serie de masacres contra la población campesina, en una campaña militar destinada a eliminar las bases sociales del Frente Farabundo Martí para la Liberación (FMLN). La confrontación llegó a su fin en 1992 e implicó la desmovilización de los combatientes guerrilleros, y la apuesta por una reforma económica estructural (Boyce, 1999).

En el período posconflicto el país vivió un aumento desproporcionado de la criminalidad debido a procesos de rearme y fracasos en el proceso de reintegración (Fundación Ideas para la Paz, 2005). A estos factores, se suma el inminente rezago institucional, principalmente del sistema de justicia y el de seguridad pública, porque el acuerdo firmado estableció la disolución de tres instituciones encargadas de la seguridad de la comunidad: la Policía Nacional, la Guardia Nacional y la Policía de Hacienda (Vesga, 2002). Además, como condición para su desmovilización, los grupos al margen de la ley pidieron una disminución de efectivos, de armamento y de recursos financieros destinados a la seguridad. Sin embargo, este condicionante generó una limitada capacidad de respuesta institucional ante el ya mencionado aumento de la criminalidad común (Pérez, 2003).

Bajo los acuerdos de paz, se plantearon entonces algunos retos en el escenario de posconflicto, entre los que estuvo precisamente la reforma a la estructura policial. Enunciemos algunos:

a. Inclusión de excombatientes en la estructura del Estado. A diferencia del caso guatemalteco, la nueva institución policial incluiría la vinculación de excombatientes en este cuerpo de uniformados (Amaya, 2007), así como su participación política y el nombramiento en cargos públicos, como fundamento de la democratización del Estado y la construcción de una nueva institucionalidad pública. Lo anterior, intentado ser consecuentes con el principio de que: 
la Policía Salvadoreña, como entidad civil creada bajo la coordinación de actores internacionales como Naciones Unidas, se enmarcaría dentro de los principios democráticos, la noción de seguridad pública como un servicio del Estado a la ciudadanía, ajeno a toda consideración política, ideológica o de posición social y subordinada a las autoridades constitucionales (Schultze-Kraft 2005, p.328).

b. Procesos de desarme. Una consecuencia grave del posconflicto en El Salvador fueron los errores cometidos por el Estado en la devolución del armamento por parte de los grupos al margen de la Ley. Como señala el Grupo de Trabajo sobre el Pos Conflicto de la Fundación Ideas para la Paz y de la Universidad de los Andes muchos excombatientes "prefirieron guardar y esconder el armamento que habían obtenido durante la conflagración" (Fundación Ideas para la Paz-Universidad de los Andes, 2002, p.3). De hecho, un informe de la ONU reportaba que casi un año después de la firma de los acuerdos, de manos civiles sólo se habían recogido 100 armas de un total calculado en varios miles. La Policía Nacional Civil reportó que "existían alrededor de 150.000 armas registradas por la ciudadanía. Sin embargo, se estima que otras, más de 120.000, están en circulación ilegalmente, pues no fueron registradas por ser de uso privativo de la FFAA" (Fundación Ideas para la Paz, 2005, p.3).

c. Retos del DDR (Desarme, desmovilización y reintegración). En los acuerdos de paz y el Plan de Reconstrucción Nacional (PRN) se consideró la creación de cuatro programas para garantizar a los excombatientes un proceso de reinserción y reintegración sostenible: a. Oferta de programas de capacitación y asistencia técnica; b. acceso a programas de vivienda y al sistema de créditos agropecuarios; c. transferencia de tierras; d. participación en el programa de integración de excombatientes a instituciones de seguridad gubernamentales. Sin embargo, "los programas no tuvieron el resultado esperado por el gobierno en la reincorporación a la vida civil exitosa y productiva de los excombatientes" (Libreros, 2012, p.21).

d. Desmantelamiento del carácter militar de la Policía. El acuerdo firmado estableció el desmantelamiento de los tres cuerpos de seguridad encargados dela seguridad: la Policía Nacional, la Guardia Nacional y la Policía de Hacienda. Dichas instituciones se encontraban adscritas al Ministerio de Defensa Nacional y, por lo tanto, con un sistema normativo del orden militar (Vesga, 2002).

\section{AFGANISTÁN}

Si bien no es posible considerar a Afganistán como un país en su totalidad en posconflicto, sí es posible extraer de su experiencia en la profesionalización de la Policía Civil y del papel de la cooperación internacional en el marco del conflicto armado, algunas lecciones.

Los comienzos del conflicto afgano pueden rastrearse, muy brevemente, en la Revolución Socialista que tuvo lugar en este país finalizando la década de los años setenta, que sería 
posteriormente amenazada por la oposición musulmana y otros grupos armados no simpatizantes del gobierno. Este proceso terminaría con la invasión soviética que contuvo el anticomunismo de los muyahidines (los luchadores por la fe islámica), quienes fueron eventualmente financiados y apoyados por EEUU, situando de este modo a Afganistán como un escenario más de conflagración durante la Guerra Fría (Insight on conflict, 2013).

Tras el desmantelamiento de la URSS, estos sectores islamistas se dividirían en facciones, permitiendo posteriormente el ascenso Talibán (que surgiría como grupo político-religioso entrada la década de 1990) y el control de estos últimos de una gran extensión del territorio Afgano en el sur y el centro del país.

A raíz del atentado al World Trade Center el 11 de septiembre de 2001, EE. UU. emprendió una campaña de bombardeos aéreos con el fin de entablar una retaliación a los ataques terroristas atribuidos a Al-Qaeda y a Osama Bin Laden. El gobierno Talibán de Kabul fue finalmente depuesto en el mes de diciembre de 2001, motivando una intervención internacional de algunos países occidentales, para desarmar las milicias, almacenar las armas pesadas, fomentar la confianza y proporcionar la seguridad para los procesos electorales.

Sin embargo, después de la aprobación del plan operacional para la Fuerza Internacional de Asistencia para la Seguridad en Afganistán en diciembre de 2005, la mencionada intervención, inicialmente orientada al desarrollo de labores de mantenimiento de la paz, comenzó a asumir y a desarrollar actividades propias de operaciones de construcción de la paz, procurando la reconstrucción del país y el desarrollo de las instituciones del Estado. Pero ante los constantes ataques de los que fueron objeto los miembros de la fuerza internacional por parte de los Talibán, la OTAN decidió realizar operaciones de combate y contrainsurgencia, que llevaron a que algunos de sus Estados no quisieran aportar nuevos contingentes militares (Manrique, 2010).

Desde 2011, con la intención de retirar las tropas extranjeras del territorio, se decidió transferir progresivamente la responsabilidad de la seguridad del país al gobierno afgano y a sus fuerzas de seguridad (Ejército y Policía), asumiendo los riesgos que esto implicaba en medio de la debilidad institucional de un Estado con bajos grados de legitimidad.

Organizaciones como Human Rights y Amnistía Internacional (Insight on Conflict, 2013) reportaron que, durante los diez años de la intervención militar en Afganistán, algunos miembros de las autoridades oficiales cometieron delitos derivados del abuso de autoridad, así como el uso sistemático de métodos degradantes, como la tortura y el maltrato a la población, justificados bajo el precepto de que todas las personas víctimas de estos hechos, eran pertenecientes a grupos insurgentes.

La conformación de la institución policial en este contexto tenía como objetivo sostener las instituciones democráticas y la erradicación de los cultivos ilícitos presentes en el territorio. Esta preocupación y la búsqueda de una solución se plasmaron en la Conferencia de Bonn, Alemania, en diciembre de 2001. Dentro de las reformas planteadas estuvieron básicamente: 
a. Redefinir la naturaleza de la Fuerza Policial. De hecho, con la adopción de la Constitución Política de la República Islámica de Afganistán el 4 de enero de 2004, se transformó la labor de la Policía y se dictaminó que su deber se enfoca en la prevención del crimen, alejándose de las funciones militares asumidas en el contexto de la guerra (Vargas, 2011).

b. Especialización de la Policía. Se conformó un cuerpo de policía integrado por tres grupos: la Policía Uniformada (AUP), la Policía de Fronteras (ABP) y la Policía Nacional de Orden Civil (ANCOP). En primer lugar, la AUP tendría la misión de garantizar el orden público y la seguridad ciudadana en todo el territorio de Afganistán, en los niveles local, provincial y regional. La Policía de Fronteras, por su parte, se organizó en cinco zonas: norte, sur, este, oeste y central; además controla los aeropuertos de Kabul, Herat y Kanda-har, así como once puestos fronterizos y una zona de 55 kilómetros hacia el interior. Y la tercera división, la Policía Nacional de Orden Civil, que constituida en 2006, se ocuparía de misiones de mayor riesgo, actuando como unidades de reserva y reacción rápida. La formaron unos 4.000 efectivos, organizados en brigadas y batallones, desplegables en todo el país, ocupados de la lucha contra el narcotráfico, terrorismo y delincuencia organizada (IBID).

c. Capacitación de los miembros de la Policía. A pesar de que más del $90 \%$ de los policías afganos son analfabetas, y los niveles de motivación entre las filas son bajos por los insuficientes salarios recibidos (80 dólares al mes para un Policía) (Pintor, 2012)), la política de profesionalización de la Policía y sus instituciones, es una de las apuestas más fuertes de cara al proceso de retirada de las tropas extranjeras en el año 2014 (Reuters, 2013. Este proceso de capacitación surge tras la decisión de transferir al gobierno afgano y sus instituciones, la responsabilidad de asumir por completo la seguridad del país (IBID).

\section{SUDÁN DEL SUR}

La situación del conflicto en Sudán surgió cuando Gran Bretaña y Egipto trazaron una Constitución para la independencia de la nación en 1956. Sin embargo, este hito marcó el inicio de la guerra civil en el Sur del País. Aunque Sudán logró retornar al régimen civil y democrático, el 30 de junio de 1989 el General Omar Hassan Ahmad al-Bashir dio un golpe de Estado que inauguró un nuevo periodo de violencia interna y consolidó el primer régimen islámico del continente africano. En estos años se vivieron enfrentamientos del orden religioso y étnico (Domínguez, 2009).

La primera Guerra que tuvo lugar entre Sudán y el hoy Estado Sudán del Sur ${ }^{4}$, se dio entre 1955 y 1972 y se desarrolló entre el gobierno de Sudán y grupos rebeldes del sur que demandaban autonomía para ese territorio. La primera guerra terminó en 1972 con el Acuerdo de Addis

4. Para ampliar información acerca de la consolidación del Estado de Sudán del Sur (Ylönen, 2013). 
Abeba, que otorgó a esta región, relativa autonomía para gestionar asuntos internos (Enough Project, s.f.) La segunda guerra detonó en 1983, por cuenta de asuntos arraigados derivados de la decisión del presidente Jaafar Nimeiris de implementar la Ley Islámica en el país. Ante ese escenario, el gobierno sudanés y el Ejército de Liberación del Pueblo de Sudán (cuyo brazo político solía ser el Movimiento de Liberación del Pueblo de Sudán) emprendieron un proceso de negociación entre 1988 y 1989, que fue interrumpido cuando el General Omar Hassan al-Bashir tomó el poder tras dar un golpe de Estado en 1989 (Enough Project, s.f.). El conflicto terminó con el Acuerdo General de Paz de 2005, (entre otras cosas, tras haber descubierto grandes yacimientos petroleros en el sur del país), con la garantía del gobierno sudanés de otorgar autonomía a esta región y representación en un gobierno nacional con el poder compartido (Domínguez, 2009).

Esta situación avivó las reivindicaciones de la población del sur, generando enfrentamientos asimétricos en todo el país y escalando a los mayores niveles de violencia en 2003. A esta confrontación, se añadió la comisión de un genocidio de carácter étnico, perpetrado por los milicianos árabes Janjaweed, (de la zona de Darfur y Chad) que descienden de las tribus Baggara y son apoyados por el gobierno sudanés, contra la población aborigen africana asentada en Darfur, al oeste de Sudán. Por esta razón la Corte Penal Internacional emitió una orden de captura contra el presidente sudanés, Al-Bashir, por crímenes de genocidio (United Human Rights Council, s.f.).

Entre el 9 y el 15 de enero de 2011, tuvo lugar un referéndum, que consultó por la permanencia o división geográfica de Sudán. Pese al fraude electoral que dio resultados totales mayores al 100\%, el 98.83\% votó por la separación del país y se proclamó la conformación de Sudán del Sur, el 9 de julio de 2011 (Delgado, s.f). La nueva República de Sudán del Sur inició su existencia enfrentando enormes desafíos, entre ellos la crisis interna como consecuencia de la guerra civil y la falta de instituciones fuertes y recursos suficientes para generar condiciones de vida digna a la población.

A pesar de lo anterior, se han desarrollado actividades dirigidas al establecimiento de relaciones con las autoridades policiales sudanesas y con los líderes locales; también se incrementó el control y la información del servicio de la policía, la investigación de las actividades irregulares de la policía de Sudán y la verificación de la situación de seguridad del retorno de los desplazados y refugiados.

En la carta "Sudán del Sur: Agenda de Derechos Humanos", Human Rights Watch y Amnistía Internacional (2011), señalaron a comienzos de la consolidación del nuevo Estado Africano, que se continuaban presentando casos de violación a los DDHH. Allí indicaban que en medio de los combates entre el Ejército de Liberación Popular de Sudán y los grupos de oposición, se cometieron graves abusos por parte de la Fuerza Pública, que incluyeron el homicidio injustificado de civiles y la destrucción de hogares de civiles. 
En términos de reformas a las estructuras policiales se han planteado los siguientes desafíos:

a. Profesionalización de las Fuerzas de Policía. En primer lugar, el principal problema que vive la policía de Sudán es su profesionalización, ya que las estructuras de seguridad civil desde la llegada al poder de Al-Bashir, se constituyeron en la concepción religiosa, de un Estado islámico, orientado hacia la organización legislativa y la creación de un Estado federal. En este sentido, las tareas de la Policía Popular eran garantizar la seguridad de la población, proteger la propiedad y participar en la aplicación de la Sharia (la senda jurídica del Islam). La policía ha sido básicamente una especie de guardiana moral (Arenas-García, 2010).

b. Consolidación de la Policía a partir de la Cooperación Internacional. Frente a la crudeza de la confrontación, la Misión de ONU en Sudán (UNMIS, por sus siglas en inglés) comenzó a operar en el país desde 2005 y en el contexto de dicha presencia fue revelado que las fuerzas policiales de Sudán del sur (SSPS), incorporando, sin verificar antecedentes, soldados que solían pertenecían al Ejército Popular de Liberación del Pueblo de Sudán (SPLA, por sus siglas en inglés) (IBID). Dado ese panorama, las fuerzas internacionales tuvieron que destinar más efectivos y recursos y por este motivo, de manera posterior, la policía, junto al personal civil, los observadores militares y ONGs, reforzaron sus actividades de escolta a la población desplazada. Se encargaron además de organizar foros sobre los derechos de las mujeres y la niñez, reuniones sobre seguridad y creación de estrategias para dar más apoyo a las víctimas del conflicto (IBID). Las acciones realizadas por la policía civil se orientaron a monitorear el cumplimiento de los acuerdos de cese al fuego, a garantizar el ejercicio las labores de cooperación, a la creación de un entorno seguro que permitiera el reparto de la ayuda humanitaria. De todas formas, la mayoría de la población en Sudán del Sur teme a la policía, en lugar de percibirla como garante de la seguridad y la convivencia.

\section{IRLANDA DEL NORTE}

Podría decirse que la religión desempeña un papel muy relevante en las raíces y las dinámicas del conflicto entre Gran Bretaña e Irlanda del Norte. En este conflicto, los católicos mayoritariamente republicanos, han reivindicado dejar de ser parte del Reino Unido de Gran Bretaña e Irlanda del Norte, mientras los protestantes son mayoritariamente unionistas y defienden la no separación de Gran Bretaña (BBC, 2005, 28 de julio).

Desde los inicios del proceso colonizador se establecieron varios asentamientos en el territorio con una pluralidad de comunidades, enfrentadas por definir quién pertenecía a la Corona Británica o a la República Irlandesa (Bew y Meehan, 1994). Estos enfrentamientos se iniciaron durante el siglo XII con las invasiones Anglo-normandas, y posterior a ello en 1920, como respuesta a la violencia de Irlanda contra Gran Bretaña, el gobierno británico dividió Irlanda en dos: Irlanda del Estado Libre, con una población católica romana, e Irlanda del Norte, protestante, que continuaba siendo parte del Reino Unido. 
La mayor acción insurgente fue promovida por el Ejército Revolucionario Irlandés - IRA, entre 1969 y 1997. En el otro bando estaba la Fuerza Voluntaria del Ulster que era Unionista (Elliott y Flackes, 1999). Esta espiral de violencia se debió a que ambos grupos se armaron en respuesta a la debilidad del Ejército y la Policía del Ulster, adscritas al gobierno británico, que en el discurso político se consideraba imparcial frente al conflicto irlandés. El acuerdo de paz que se propuso en Irlanda del Norte tenía como pretensión conformar un gobierno compartido por católicos y protestantes. Se convirtió, por tanto, en la solución para poner fin a cientos de bajas de las fuerzas militares británicas y de los grupos armados de ambos bandos, que además contaban con un enorme arsenal que causó la destrucción de múltiples poblaciones en la Gran Bretaña, pero de manera principal en Irlanda del Norte (IBID).

En este desenlace es fundamental el rol de la Policía, porque el Acuerdo de Viernes Santo, también conocido como Acuerdo de Belfast y firmado el 10 de abril de 1998, planificó varias acciones, una de las primeras fue la liberación masiva de prisioneros que en su mayoría retornaron a sus comunidades de origen. Varios miembros de las comunidades católicas vieron en los ex combatientes una salida a los problemas de inseguridad. Pese a los cambios políticos y de los miles de proyectos locales para lograr la integración, la cultura de la sospecha y la cultura del recelo hacia la autoridad aún sigue viva en gran parte de las comunidades católicas 5 .

En el caso de Irlanda del Norte, el conflicto armado dejó como saldo el asesinato en circunstancias violentas de más de 3.600 personas, de los cuales fueron responsables tanto miembros de los grupos armados ilegales, como agentes del Estado británico (Amnistía Internacional, 2012). Unos de los hechos que mejor ilustra este aspecto, es el caso de la muerte de seis hombres en una operación conocida como shoot-to-kill policy, suceso que respondía a una política oficial de asesinatos a miembros de grupos armados de oposición.

En este conflicto, una iniciativa central en el proceso de construcción de paz fue las de Comunidades de Justicia Restaurativa (CRJ) por sus siglas en inglés. Aun así, el problema de este tipo de experiencias es que con la reforma policial, la concepción original de la justicia restaurativa en el contexto de la Irlanda del Norte, como una forma de hacer justicia contrapuesta a la justicia retributiva y por tanto al trabajo de la policía, deja de tener sentido ${ }^{6}$. Por tal motivo, como han reconocido Herrera y Bello "es posible pensar que esquemas como la CRJ pueden tener futuro en la medida en que se conciban como mecanismos complementarios y no sustitutivos de la justicia tradicional" (Herrera y Bello, 2010: 137).

5. El trabajo de Wilson y Stapleton (2007) es interesante para mirar esta cultura del recelo a partir de un análisis de los "discursos de resistencia" al nuevo cuerpo de policía por parte de mujeres en Belfast.

6. Algunos autores como Cusack (2009) en el caso de Irlanda han llamado la atención sobre la necesidad de abordar en las escuelas las funciones de la actividad policial a través de programas de educación para la reconciliación. Clave este tema para el caso colombiano. 
Como resultado de los acuerdos se acometieron una serie de reformas en el marco de la institucionalidad policial, que vale la pena destacar aquí:

a. Construcción de confianza. En cuanto a la estructura del servicio de policía, este fue un gran reto debido a la desconfianza de buena parte de la población católica en el Ulster pues el accionar de la policía en contra de la institución y de la población protestante fue lo que obligó a incorporar al Ejército en la defensa de la población y el combate contra el terrorismo. Algunos analistas han señalado, que

La razón se fundaba en su participación activa en el conflicto, debido a que estuvo integrada tradicionalmente por miembros protestantes del partido unionista. Lo que la hizo proclive a una aplicación parcializada de las normas de seguridad y orden público a favor de los unionistas y en contra de los nacionalistas. Por tal motivo, el acuerdo estableció la constitución de una comisión asesora, integrada por expertos internacionales en el tema, que formularan las recomendaciones necesarias para crear un servicio de policía profesional, independiente e imparcial capaz de lograr la confianza de toda la comunidad (Herrera y Bello, 2010, p.114).

b. Reestructuración del cuerpo de Policía. La constitución de los Servicios de Policía en el Norte de Irlanda (PSNI), el surgimiento de cuerpos colegiados y otras instituciones autónomas, como la Comisión Independiente para la Policía, la Junta de Policía y el Ombudsman policial, beneficiaron una reforma estructural al trabajo de las fuerzas encargadas del cumplimiento del orden. En conclusión, la creación de estas instituciones de control y acompañamiento de la Policía fueron fundamentales para transformar la percepción de la población, en gran parte porque se hizo paritaria entre católicos y protestantes y asumió el manejo de la seguridad en su totalidad con un criterio puramente civil (Deverell, 2008).

c. Elaboración de un Código de Ética policial. A diferencia de los otros países, en el caso Irlandés, la reforma del cuerpo policial fue evidente gracias a la elaboración de un código de ética, el cual fue aprobado en la nueva ley de 2001. Este código trajo consigo también cambios simbólicos en su iconografía, lo mismo que el juramento que deben prestar los funcionarios, para minimizar la idea del predominio colonial británico. Según Gabaldón y Antillano durante este proceso de reforma:

La participación de la policía fue importante, y según algunas fuentes, contribuyó con el $70 \%$ de las propuestas de reforma, además de redactar el borrador del Código de Ética para la Policía, que establece principios y procedimientos sobre el deber profesional, la investigación policial, la privacidad, el uso de la fuerza, el tratamiento de los detenidos, igualdad, integridad, honestidad y decoro (Gabaldón y Antillano, 2008, p.11). 


\section{LA PRINCIPAL LECCIÓN: UNA NUEVA ORGANIZACIÓN POLICIAL MÁS CIVIL Y MENOS MILITAR}

Comparativamente hablando, es posible ver en cada uno de los casos expuestos una reivindicación concreta en función de ciudadanizar la institución, bien sea en términos de apelar a su originaria naturaleza civil o superar y revertir los casos en los cuales han actuado en contra de la ley en medio de las hostilidades. Por otro lado, la revisión realizada permite encontrar algunas similitudes en las vías de acción elegidas por los gobiernos en el periodo de la transición; sin embargo, no provee de protocolos estandarizados de reformas que puedan ser aplicadas en cualquier contexto. Cada uno de los conflictos brevemente mencionados revela las particularidades de los marcos y condiciones históricas, así como los requerimientos exigidos por la superación de violencias concretas, conectado todo ello a contextos geográficos, sociales, económicos, temporales, y políticos distintos.

Los casos de Afganistán y Guatemala revelan cómo las instituciones encargadas del orden público tienen que ser puestas en control y vigilancia de entidades diferentes a las de corte militar. Es decir, vigiladas por instituciones del orden civil, especialmente para evitar lo que sucedió en el caso guatemalteco y es que, como han reconocido algunos autores, entre ellos Ziegler (2002) los archivos para 1997 y 1999 revelan que ningún oficial fue sancionado por abuso de un civil y que ningún caso iniciado por un civil concluyó en sanciones para los involucrados. Este sistema ha facilitado el sostenimiento de una fuerza policial altamente militarizada en Guatemala y permite serios abusos contra policías al interior de la fuerza policial por parte de sus superiores.

En el caso guatemalteco, el que después de los acuerdos de paz la institución de la Policía Nacional Civil pasara bajo el Ministerio de Gobernación y no bajo el Ministerio de Defensa, permitió la superación de las actividades militares de las policiales. Es decir, la búsqueda fue por un servicio público para la comunidad con el fin de garantizar la vida, la integridad, el patrimonio, así como el ejercicio de los derechos y libertades ciudadanas (Oliva, 2012). A su vez, el papel de la sociedad civil en el establecimiento de la seguridad se vio protagonizada por el establecimiento de las Juntas Locales de Seguridad (JLS) hacia finales de los años noventa. A pesar de esto, estos cuerpos siempre generaron sospecha al ser conformados por reinsertados responsables de delitos durante el conflicto contrainsurgente ${ }^{7}$.

Por su parte, en el caso salvadoreño, en el Ministerio de Gobernación, hoy Ministerio de Seguridad Pública y Justicia se concentró el control y dirección de las políticas de seguridad en el país. La democracia estaría respaldada por la Policía Nacional Civil ${ }^{8}$ la cual estuvo bajo la dirección de un civil designado por el presidente. La reconstrucción de la paz exigió la reingeniería de la institución policial a través del recorte de personal, la profesionalización de

7. Se recomienda ver informe del Procurador de los Derechos Humanos de Guatemala (PDH, 2009).

8. Esto ha sido puesto en cuestión en Bayley (2008). 
los uniformados y una nueva administración que buscó la promoción de políticas de prevención del delito con unas políticas institucionales más o menos claras. Además, se promovieron planes de seguridad que pretendieron detener las bandas delincuenciales dentro de los centros urbanos y con el apoyo del FBI, se orientaron políticas destinadas a detener fugitivos, reforzar la coordinación internacional, compartir información y capacitar a los agentes (Bonilla, 2008).

En el caso de Irlanda, como se señaló anteriormente el papel de la Policía en la constitución de un escenario democrático para las confesiones religiosas, fue un reto, debido a la desconfianza de buena parte de la población católica en el Ulster. En este escenario sobresalía la necesidad de constituir un sistema de rendición de cuentas en la policía que permitiera escenarios de gobernanza de este tipo de institucionalidad.

Para el caso de Afganistán la presencia de las organizaciones militares internacionales ayudó a la conformación de un cuerpo cívico policial. Donde sobresalió la necesidad de desarmar las milicias, almacenar las armas pesadas, fomentar la confianza y proporcionar la seguridad a las elecciones. El replanteamiento de las políticas de seguridad en el territorio tuvo entre sus metas la formación de 3.500 policías afganos, buscando pasar de una estrategia de confrontación belicista a una estrategia comunitaria que creara tejidos entre el gobierno y la ciudadanía. Sin embargo, esta labor resultó muy difícil de lograr por los bajos salarios (EuropaPress, 2009) asignados al personal policial, por el alto nivel de riesgo, la corrupción y el consumo de drogas presente en la institución.

Llama la atención, a partir de un informe elaborado por el Departamento de Estado de EEUU y el Pentágono en 2006, la preocupación por la gestión de los 1.100 millones de dólares destinados al plan de entrenamiento de la policía afgana. Esto fue motivado por la permanente inseguridad del territorio, donde no existía una cifra fiable de efectivos capacitados; igualmente se desconoce el rumbo de las ayudas en equipamiento de la fuerza policial. Este informe señaló que de los 70.000 policías Afganos, tan solo un $40 \%$ estaba realmente capacitado para su labor. Del mismo modo, alertó sobre infiltración talibana (Glanz y Rohde, 2006) en los reclutamientos y los altos costos que asumió la cooperación internacional para hacer sostenible la capacitación por lo menos una década más, máxime cuando las tropas extranjeras previeron retirarse en 2014. En este caso, la estrategia ha sido una triada de objetivos interconectados: seguridad, gobernanza y desarrollo, reconociendo la dimensión política de la solución y el papel de la población (Marzá, 2010).

En el caso de Sudán, habría que tener en cuenta que la islamización del aparato de seguridad, la llamada Seguridad Islámica, que generó una dimensión de represión política. Ese aparato incluía a la Guardia de Seguridad de la Revolución, considerado por algunos analistas como "el más involucrado en la represión política conocido por las torturas practicadas en las denominadas casas de fantasmas o buyut al-ashbah y al margen de cualquier control judicial" (Ortega, 2011; Arenas-García, 2010). 
Esta situación favoreció la victimización de las poblaciones no musulmanas de Sudán, planteando la sustitución de la policía sudanesa y la necesidad del componente civil de ella. Uno de los principales aprendizajes de este proceso, es la necesidad de convertir una institucionalidad sesgada en un cuerpo policial moderno, que respete los DDHH y cumpla los estándares internacionales de conducta (Alaminos, 2008).

\section{CONCLUSIÓN}

La revisión de literatura permite corroborar la hipótesis planteada al inicio del texto y es que de manera diferenciada en cada uno de los casos analizados, la Policía jugó un papel fundamental en el marco de los conflictos internos.

Ya sea por, políticas oficiales como por comportamientos personales, se ejecutaron acciones contrarias a la defensa de los DDHH y a la seguridad ciudadana, lo que hizo necesario replantear sus funciones en los escenarios posconflicto.

Precisamente, una de las recomendaciones centrales en el posconflicto colombiano, o en un escenario de pos acuerdos, es que esta institución debería ser una de las primeras afectadas en su transformación, dado que el mantenimiento tanto de algunos de sus miembros como de políticas militares, genera desconfianza entre la población.

De hecho los acuerdos de paz, o las transiciones pactadas o los momentos posacuerdo, exigirán por ejemplo, una sólida formación profesional de sus miembros y la construcción de políticas educativas reconciliadoras que permitan tejer puentes y densificar las confianzas mutuas entre la ciudadanía y la institucionalidad. Ciudadanizar radicalmente la policía sería una vía en este sentido.

Además, un escenario posacuerdo exigirá pensar en la viabilidad de judicializar a los miembros de la antigua estructura que hayan ocasionado delitos contra la población civil.

En este caso, serán principalmente instituciones internacionales promotoras de los DDHH como Amnistía Internacional o Naciones Unidas, al igual que las organizaciones de víctimas, las que se convertirán en protectoras o guardianes de lo pactado. Ellas serán claves para mantener la memoria de victimización, pero también las memorias transformadoras en clave de posconflicto en toda la sociedad colombiana.

Así mismo servirán para garantizar que los mecanismos de asignación de responsabilidades judiciales y sociales operen bajo las consignas de la búsqueda de la verdad, de la justicia y de la reconciliación.

Ante los abusos del cuerpo de Policía durante el conflicto, una posible salida, aunque no la única, sería la creación de mecanismos de control posacuerdo, que permitan mayor veeduría y participación por parte de la sociedad civil. 


\section{REFERENCIAS}

Alaminos, M. (2008). El conflicto de Darfur: un reto para la credibilidad de la Unión Africana. UNISCI Discussion Papers, 16, 229-253.

(2012). El Salvador's brutal civil war: What we still don't know, twenty years after peace accords were signed, many aspects of El Salvador's long civil war remain murky. [En línea]

Amaya, E. (2007). Quince años de reforma policial en "El Salvador: avances y desafíos". URVIO, Revista Latinoamericana de Seguridad. No 2, Pp.127-144

Amnistía Internacional (2012). El estado de los derechos humanos en el mundo. (Informe 2012). Recuperado de http://files.amnesty.org/air12/air_2012_full_es.pdf.

Arenas-García, N. (2010). The UNMIS in South Sudan: Challenges \& Dilemmas en Documentos lecah, document 5. [En línea], disponible en: http://iecah.org/web/images/stories/ publicaciones/documentos/descargas/documento5_en.pdf.

Bayley, D. (2008), "Post-conflict Police Reform: Is Northern Ireland a Model?", Policing, June 5, pp 233-240.

Bew, P. y Meehan, E. (1994). Regions and Borders: Controversies in Northern Ireland about the European Unión'. Journal of European Public Policy, 1, (1): 95-113

Bonilla, O. (2008). Las reformas al sector seguridad en América Latina y el impacto de las amenazas irregulares: el caso de El Salvador. En: Reforma de las fuerzas armadas en América Latina y el impacto de las amenazas irregulares, Editor José Raúl Perales. Washington, Woodrow Wilson International Center for Scholars

Boyce, J. (1999). La política económica de posguerra en El Salvador En Boyce, James (coordinador). Ajuste hacia la Paz: La Política Económica y el desarrollo, México, Plaza y Valdez Editores.

Contreras, A. y Sinay Álvarez, F. (2004). Historia de la Policía Nacional de Guatemala, 18811997. Tesis Escuela de Historia, Guatemala, Universidad de San Carlos de Guatemala.

Comisión de Esclarecimiento Histórico (CEH) (1999). Guatemala: Memoria del Silencio. 12 Tomos.

Cruz, J. (2006). Maras y pandillas en Centroamérica Las respuestas de la sociedad civil organizada. El Salvador, UCA Editores. 
Cusack, Mella (2009) Policing Matters: "Addressing the Controversial Issue of Policing through Education for Reconciliation", International Review of Education, Vol. 55, No. 2/3, pp. 251-267.

Delgado, J. (s.f) Un año después Sudán del Sur y la independencia. Análisis Geopolítico 4. Centro de pensamiento estratégico. Ministerio de Relaciones Exteriores. [en línea], disponible en: http://www.cancilleria.gov.co/sites/default/files/pensamiento_estrategico/documentos geopolitica/c.\%20Un\%20a\%C3\%B1o\%20Despues,Sudan\%20del\%20Sur\%20y\%20su\%20 Independencia-Julio2012.Jeronimo\%20DELGADO.pdf

Deverell, J. (2008). Lecciones de la campaña contrainsurgente en Irlanda del Norte. En: Llorente, María Victoria; Ortiz, Román y Urrutia, Nicolás. Policía Nacional: Una fuerza para la consolidación. Fundación Ideas para la Paz. Preprensa e impresión Zetta. Bogotá D.C, Disponible en: www.ideaspaz.org/portal/images/propuestas_policia.pdf.

Domínguez, C. (2009). "El conflicto en Darfur: Autodeterminación, colonialismo interno y separatismo etnopolítico en los primeros años del siglo XXI". Revista Estudios de Asia y África, 44(1): 105-120.

Elliot, S. y Flackes, W.D. (1994). Northern Ireland: A Political Directory, 1968-1993. Blacksta, Belfast.

Enough Project(s.f), Sudan and South Sudan, [en línea], Disponibleen: http://www.enoughproject. org/conflicts/sudans.Research Unit on International Security and Cooperation (UNISCI Discussion Papers No 16). España, Universidad Complutense de Madrid.

EuropaPress (2009), La formación de Policía afgana, primera línea de defensa en los comicios, prioritaria para la OTAN, [en linea], disponible en: http://noticias.lainformacion.com/ politica/defensa/la-formacion-de-policia-afgana-primera-linea-de-defensa-en-loscomicios-prioritaria-para-la-otan_1pJ2opd49wA7eP1VdjV4E5/

Fundación Ideas para la Paz - Universidad de los Andes (2002). Una sociedad en armas, el postconflicto en el Salvador [en línea], disponible en: http://homepage.univie.ac.at/Miguel. Gamboa/Texte/el_salvador.pdf.

Fundación Ideas para la Paz (2005). Desmovilización y reinserción en El Salvador. Reporte preparado Lecciones para Colombia. Bogotá, Fundación Ideas para la Paz.

Gabaldón, L. y Antillano, A. (2008). “Las reformas policiales en Irlanda del norte y en Venezuela: Una visión comparada". Capítulo Criminológico. 36(3), pp.5-27.

Glanz, J y Rohde, D, (2006). Caos en la Policía Afgana. 5 de diciembre de 2006 New York. En: El País, España. Disponible en: http://elpais.com/diario/2006/12/05/ internacional/1165273212_850215.html 
Gonzales, L y Romano L, (2000). Reforma agraria y cooperativismo en El Salvador: antecedentes y perspectivas (1970-1996). El Salvador, UCA.

Herrera, W y Bello G, (2010). "El proceso de paz en Irlanda: un modelo de justicia transicional desde abajo; El tránsito hacia la paz: de las herramientas nacionales a las locales. Bogotá, Universidad de Rosario.

Human Rights Watch y Amnistía Internacional (2011). Sudán del Sur: Agenda de derechos humanos. Disponible en: http://www.hrw.org/sites/default/files/related_material/South\%20 Sudan-\%20Human\%20Rights\%20Agenda,\%206-30-11,\%20SP.pdf

Insight on conflict (2013) Afghanistan: Conflict profile. Disponible en: http://www. insightonconflict.org/conflicts/afghanistan/conflict-profile/

Jaramillo, J (2009). "Tres procesos emblemáticos de recuperación de pasados violentos en América Latina: Argentina, Guatemala y Colombia". Revista Virajes, 11: 29-59.

Kalyvas, S, (2004). "La ontología de la 'violencia política': acción e identidad en las guerras civiles", Análisis Político, sep.-dic, pp.51-76. Bogotá, IEPRI.

Libreros J, (2012), Experiencias internacionales en manejo de la violencia posconflicto: Guatemala en Atmósfera política, gobierno y democracia en América Latina, [en línea], http://www.atmosferapolitica.com/2012/08/31/experiencias-internacionales-en-manejode-la-violencia-posconflicto-guatemala/.

Manrique, M (2010). "La política exterior española en África: momento de recalibrar el enfoque". Serie FRIDE Policy Brief No 46. Madrid.

Marzá, M. (2010). Reflexiones en torno a la nueva estrategia estadounidense para Afganistán. Anuario de derecho internacional. 26. Pp. 233-250. Disponible: http://dspace.unav.es/ dspace/bitstream/10171/22063/1/ADI_n\%C2\%BA\%2026_2010_07.pdf.

Oliva, J, (2012). Reforma policial en Guatemala. Universidad Panamericana. Tesis de Derecho. Facultad de Ciencias Jurídicas, Sociales y de Justicia. Disponible en: http://upana.edu.gt/ web/upana/tesis-juridicas/doc_view/1290-reforma-policial-en -Guatemala

Ortega, R. (2011). "Islamismos y Estado en Sudán: cohesiones y rupturas". Revista Cultura y Religión, 5(1): 156-180.

Pintor, T (2012) Estrategia Afgana de desarrollo, retos en su ejecución y mecanismos de coordinación. Grupo de Trabajo 2. Disponible en: http://www.ceseden.es/noticias/ pdfs/2Estrategia\%20afgana\%20de\%20desarrollo.pdf. 
Perez, O, (2013), "Democratic Legitimacy and Public Insecurity: Crime and Democracy in El Salvador and Guatemala", Political Science Quarterly, V 118, pp.627-644.

Procurador de los Derechos Humanos - PDH (2009). Informe Anual Circunstanciado al Congreso de la República. Tomo I. Situación de los derechos humanos en Guatemala durante el 2009. Guatemala: Procurador de los Derechos Humanos. Disponible en: http://www.pdh. org.gt/accesinfo/images/downloads/2009/informe2009.pdf

Ramírez, E. (2007). La legitimidad del pago a los ex Patrulleros de Autodefensa Civil. Tesis de licenciatura, Guatemala, Universidad Rafael Landívar.

Reuters (2013). "Los crímenes de lesa humanidad de la Otán". Agencia EFE, Kabul 07/04/2013, Disponible en: http://www.semanario-alternativas.info/archivos/2013/4\%20abril/262/ PORTADA/Articulos/crimenes_de_la_OTAN.html

Rostica, J (2006). "La memoria en Guatemala: sobre comisiones de verdad y el hallazgo del archivo de la Policía Nacional". En: Revista Question 1(10), pp. 1-23.

Sanford, V, (2003). Buried Secrets: Truth and Human Rights in Guatemala. Palgrave/Macmillan: New York.

Schultze-Kraft, M. (2005): Pacificación y Poder Civil en Centroamérica, las relaciones cívicomilitares en el posconflicto. Colombia, Norma

Sieder, R, (2003), “Renegociando la 'ley y el orden': reforma judicial y la respuesta ciudadana en la Guatemala de posguerra. Democratization, Vol. 10 (4): 137-160. Disponible en: http:// www.rachelsieder.com/renegociando-la-ley-y-el-orden-reforma-judicial-y-la-respuestaciudadana-en-la-guatemala-de-posguerra/

United Human Rights Council (sf). Genocide in Darfur. Disponible en: http://www. unitedhumanrights.org/genocide/genocide-in-sudan.htm

Uribe, Mauricio. (2013) La nación vetada: estado, desarrollo y guerra civil en Colombia, Bogotá, Universidad Externado de Colombia.

Vargas, P, (2011),Teniente Coronel de la Guardia Civil Diplomado de Estado Mayor. POMLT: "Formación y Asesoramiento a la Policía Afgana". Editorial: Revista Ejército No. 839 Marzo 2011. España. Disponible en: http://www.belt.es/expertos/home2_experto.asp?id=5689

Vesga, N, (2002). Una sociedad en armas: el posconflicto en El Salvador. Grupo de trabajo sobre el posconflicto. Fundación Ideas para la Paz, Bogotá, Universidad de los Andes. Disponible en: http://homepage.univie.ac.at/Miguel.Gamboa/Texte/el_salvador.pdf 
Wilson, J y Stapleton, k. (2007) "The Discourse of Resistance: Social Change and Policing in Northern Ireland", Language in Society, Vol. 36, No. 3, pp. 393-425.

Ylönen, A, (2013), "Building a State without the Nation? "Peace-through- Statebuilding" in Southern Sudan, 2005-2011", UNISCI Discussion Papers, N 33, pp 13-34.

Ziegler, J. (2002). Report of the Special Rapporteur of the Commission on Human Rights on the Right to Food (Report to the Un General Assembly). http:/www.unhchr.ch/Huridocda/ Huridoca.nsf/0/990d43116ffe0be1c1256c5d00368067/\$FILE/N0254654.pdf. 